\title{
Frequency-dependence of Psychophysical and Physiological Responses to Hand-transmitted Vibration
}

\author{
Michael J. GRIFFIN ${ }^{1}$ \\ ${ }^{1}$ Human Factors Research Unit, Institute of Sound and Vibration Research, University of Southampton, United \\ Kingdom
}

Received August 18, 2011 and accepted August 2, 2012

\begin{abstract}
This invited paper reviews experimental studies of the frequency-dependence of absolute thresholds for the perception of vibration, equivalent comfort contours, temporary changes in sensation caused by vibration, and reductions in finger blood flow caused by hand-transmitted vibration. Absolute thresholds depend on the contact conditions but for a typical hand grip the thresholds show greatest sensitivity to acceleration around $125 \mathrm{~Hz}$. The frequency-dependence of discomfort caused by hand-transmitted vibration depends on vibration magnitude: similar to absolute thresholds at low magnitudes, but the discomfort at higher magnitudes is similar when the vibration velocity is similar (at frequencies between about 16 and $400 \mathrm{~Hz}$ ). Hand-transmitted vibration induces temporary elevations in vibrotactile thresholds that reflect the sensory mechanisms excited by the vibration and are therefore highly dependent on the frequency of vibration. Handtransmitted vibration reduces finger blood flow during and after exposure; when the vibration velocity is similar at all frequencies there is more vasoconstriction at frequencies greater than $63 \mathrm{~Hz}$ than at lower frequencies. A single frequency weighting cannot provide a good indication of how all effects of hand-transmitted vibration depend on vibration frequency. Furthermore, a single frequency weighting provides only an approximate indication of any single response, because many factors influence the frequency-dependence of responses to hand-transmitted vibration, including the magnitude of vibration, contact conditions, and individual differences. Although the frequency weighting in current standards extends from 8 to $1,000 \mathrm{~Hz}$, frequencies greater than $400 \mathrm{~Hz}$ rarely increase the weighted value on tools and there is currently little psychophysical or physiological evidence of their effects.
\end{abstract}

Key words: Vibration, Hand, Perception, Comfort, Vascular, Syndrome, Vibration-induced white finger

\section{Introduction}

Prolonged regular exposure to hand-transmitted vibration results in physiological and pathological disorders among those using a wide variety of vibratory handheld tools in many different occupations. The disorders

E-mail: M.J.Griffin@soton.ac.uk

(C)2012 National Institute of Occupational Safety and Health are complex, moderated by many factors, and may only appear after many years of exposure to vibration. The disorders are associated with exposures to vibration that are also complex (varying in magnitude, frequency, direction, and duration) and vary over time. A recognition of the complexity of the various cause-effect relationships easily leads to the conclusion that they cannot be unravelled, and then expressed quantitatively with any precision, solely by epidemiological studies of those occupationally exposed 
to hand-transmitted vibration.

Epidemiological studies mostly assume effects of handtransmitted vibration can be predicted from one measure, or a very small number of alternative measures, of vibration exposure. A measure of vibration severity should take into account the relative importance of different magnitudes of vibration, different frequencies of vibration, different directions of vibration, and different durations of vibration exposure. This may be achieved by assuming 'weightings' for different frequencies and directions of vibration and calculating, for example, 'frequency-weighted' accelerations in one direction, or a summation of values in three directions (e.g., the root-sums-of-squares, r.s.s.). To take the duration of exposure into account, exposures may be summed over a day (e.g., 8-h equivalent exposures, $A(8)$ ), or over a life-time (e.g., years of exposure). Depending on the assumed weightings and methods of summation, many different measures of exposure severity can be obtained and their relationships to observed disorders can be investigated in epidemiological studies. Such studies are required to test relationships, but the multiplicity of co-varying independent variables with poorly-understood roles renders epidemiological studies insufficient to develop the measure of vibration severity to be used in a dose-response relationship.

Some weightings (e.g., for frequency, direction, and duration) and some methods of summation (e.g., over frequency, direction, and duration) can be investigated experimentally with humans, especially in studies of short-term subjective and physiological responses to vibration. Studies that do not damage the participants will not directly establish what vibration is required to cause damage. However, such studies can contribute candidate methods for quantifying vibration severity and, most usefully, an understanding of some of the underlying responses to vibration, leading to models of the mechanisms associated with the damage caused by occupational exposures to hand-transmitted vibration.

This invited paper seeks to summarise the understanding that is emerging from studies of how psychophysical and physiological responses to hand-transmitted vibration depend on the frequency of vibration. The paper was prepared to assist discussions of alternative frequency weightings during the $12^{\text {th }}$ International Conference on Hand Arm Vibration in Ottawa in June 2011. Of the studies that have systematically explored the influence of the frequency of vibration, the paper focuses on results from comparable conditions that provide a coherent, although incomplete, picture of the nature of, and reasons for, some of the psychophysical and physiological responses to hand-transmitted vibra- tion. For these studies to provide a foundation on which to build a method of predicting the risks of any one of the occupational disorders caused by hand-transmitted vibration it is necessary to establish, or assume, a relation between the psychophysical or physiological responses and the occupational disorder. Irrespective of occupational injuries, improved understanding of psychophysical and physiological responses to vibration has some immediately apparent practical benefits (e.g., optimising vibration perception and minimising vibration discomfort) and may have other unpredictable benefits that arise from a better understanding of how the human body responds to vibration.

\section{Subjective Responses to Vibration}

A subjective response may indicate whether vibration can or cannot be felt. If vibration is felt, a subjective response can indicate the severity of the sensation, the type of sensation, and the location of the sensation.

\section{Thresholds for perceiving vibration}

Mechanisms for perceiving vibration

Various physiological mechanisms mediate the perception of vibration. Understanding of tactile perception comes from anatomical, neurophysiological, and psychophysical studies. The differing disciplines have resulted in differing terminologies for referring to the different systems.

The skin of the palm of the hand has mechanoreceptors with distinct properties classified as having fast or slow adaptation (FA or SA), and small or large receptive fields (type I or type II). Electrophysiological studies have shown that the fast-adapting units, FA I and FA II, have different properties to the slow-adapting units, SA I and SA II ${ }^{1}$. There is a greater density of FA I and the SA I receptors in the glabrous skin at the distal ends of the fingers, whereas the FA II and the SA II receptors are more evenly distributed. The FA I receptors are associated with Meissner corpuscles, FA II with the Pacinian corpuscles, SA I with Merkel discs, and SA II with the Ruffini endings ${ }^{2)}$. Studies of neural responses from nerve cells in humans and other animals have investigated physiological thresholds of isolated corpuscles to different types of stimuli. The SA units tend to be the most sensitive units at frequencies less than $5 \mathrm{~Hz}$, FA II units are most sensitive in the range 100 to $300 \mathrm{~Hz}$, and FA I units have a relatively flat response in which they may be more sensitive than other units over the range 10 to $20 \mathrm{~Hz}$ (Fig. $1{ }^{3)}$ ).

From psychophysical studies with humans, it gradually became apparent that the perception of vibration was 


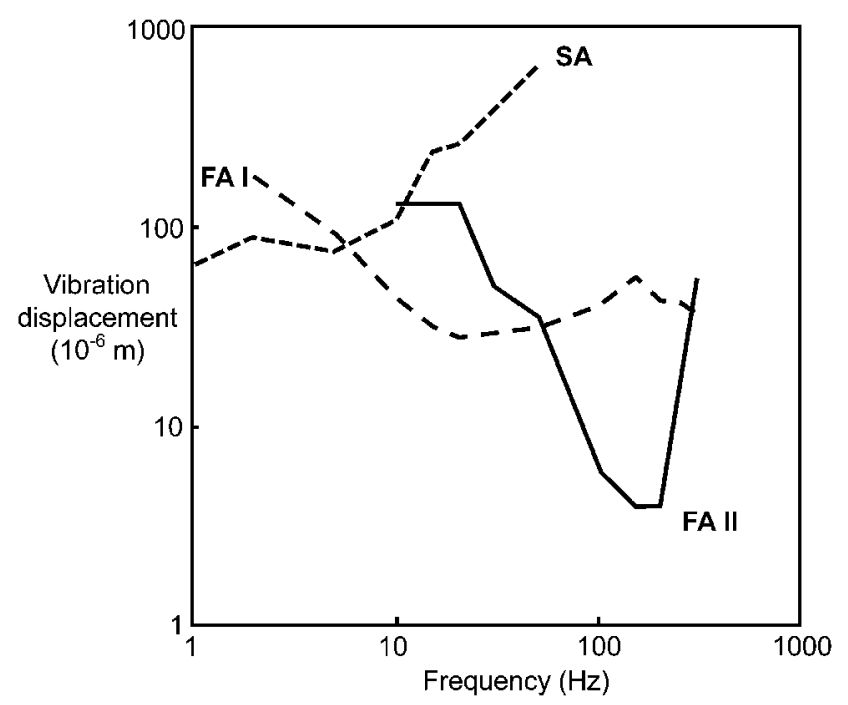

Fig. 1. Tuning curves for glabrous skin in the cat (redrawn from ${ }^{3)}$ ).

mediated by more than one mechanism and so the concept of 'psychophysical channels' emerged. Bolanowski et $a l .{ }^{4)}$ and Gescheider et al. ${ }^{5)}$ suggested four channels are involved in the perception of vibration at the thenar eminence of the hand: the slow-adapting non-Pacinian III channel is likely to be most sensitive at frequencies less than about $2 \mathrm{~Hz}$, the fast-adapting non-Pacinian I channel may mediate perception at thresholds levels between approximately 2 and $40 \mathrm{~Hz}$, the fast-adapting Pacinian channel often mediates perception at frequencies greater than about $40 \mathrm{~Hz}$, and the slow-adapting non-Pacinian II channel is sensitive in a frequency range similar to the $\mathrm{P}$ channel, but has a sensitivity lower than the $\mathrm{P}$ channel with most contact conditions (Fig. 2). The response of the Pacinian channel, with absolute thresholds for displacement and acceleration having a U-shaped frequency-dependence and greatest sensitivity in the range 100 to $300 \mathrm{~Hz}$, is often dominant in glabrous skin. Understanding of the channels involved in the perception of vibration in non-glabrous hairy skin is somewhat limited.

The terminology remains confusing, but with the following assumed associations:

- Meissner corpuscles - Non-Pacinian I (NP I) - Fast Adapting I (FA I)

- Pacinian corpuscles - Pacinian (P) - Fast Adapting II (FA II)

- Merkel discs - Non-Pacinian III (NP III) - Slow Adapting I (SA I)

- Ruffini endings - Non-Pacinian II (NP II) - Slow Adapting II (SA II)

The differing properties of the channels can have a

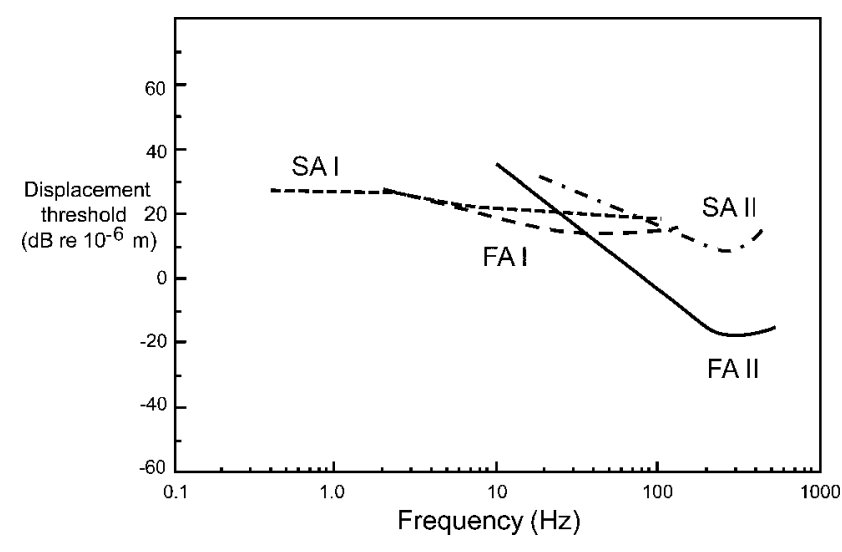

Fig. 2. Four-channel psychophysical model showing the threshold frequency response of each channel (redrawn from ${ }^{4,5}$ ).

large influence on the frequency-dependence of vibration perception. According to the contact area, stimulus duration, skin temperature, vibration magnitude, etc., different receptors or channels may dominate the response, so giving rise to a different frequency-dependence according to the contact area, stimulus duration, skin temperature, vibration magnitude, etc. The dependence of thresholds on these variables is illustrated for experimental studies having broadly comparable conditions in the next sections.

Frequency-dependence of thresholds for hand-transmitted vibration

Although contact conditions can influence thresholds for the perception of hand-transmitted vibration, different studies have produced broad agreement on the frequencydependence ( ${ }^{6}$; Fig. 3).

\section{Effect of vibration direction}

The transmission of vibration to the hand differs between directions, but absolute thresholds for the perception of hand-transmitted vibration are broadly similar for the three directions of translational vibration (6); Fig. 4).

\section{Effects of contact conditions}

Thresholds for the perception of vibration in the palm of the hand pushing down on a flat surface that vibrates vertically are broadly similar to thresholds when the hand grips a cylindrical handle that vibrates vertically ${ }^{(7)}$; Fig. 5). However, high frequency thresholds are raised (i.e., less sensitivity) and low frequency thresholds are lowered (i.e., increased sensitivity) when the vibration is applied to the skin via a small vibrating contactor surrounded by a rigid surface in contact with the skin. This is because perception 


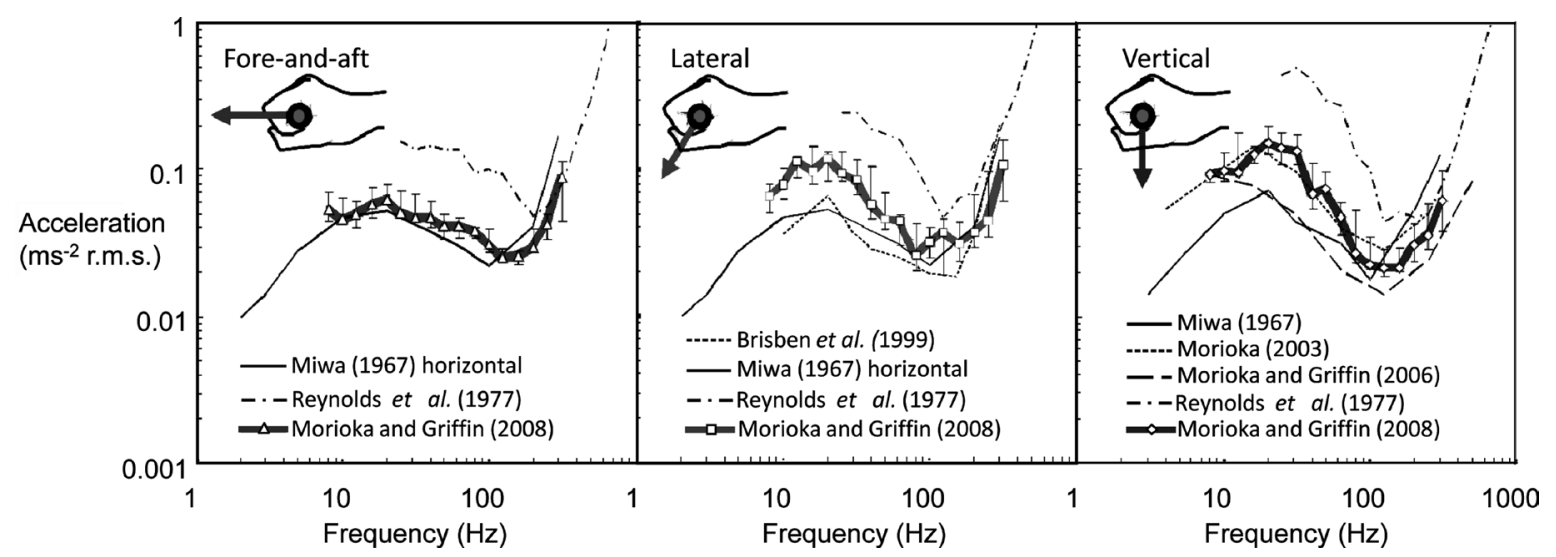

Fig. 3. Comparison of median absolute thresholds for vibration perception for each of the three axes of translational vibration at the hand (adapted from ${ }^{6)}$ ).

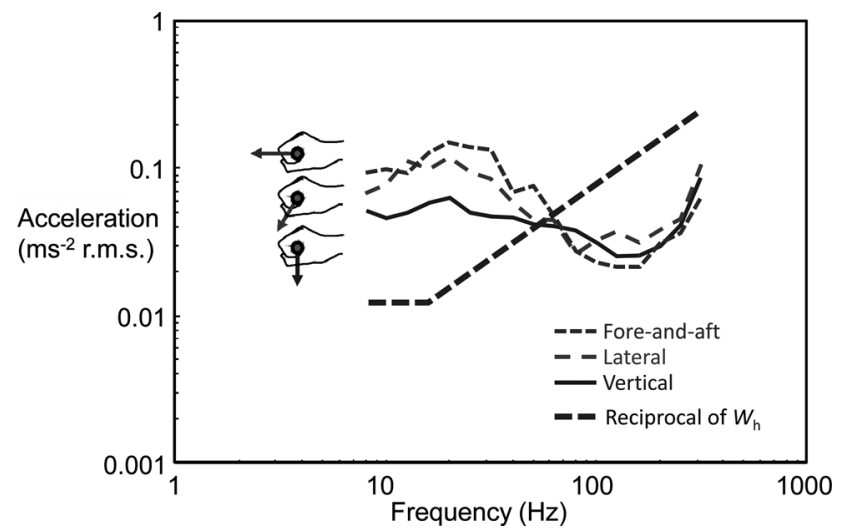

Fig. 4. Comparison of median absolute perception thresholds between the three axes of vibration of the hand with the reciprocal of frequency weighting $W_{\mathrm{h}}$ normalised to $0.01 \mathrm{~ms}^{-2}$ r.m.s. (redrawn from ${ }^{6)}$ ).

of high frequency vibration is mediated via the Pacinian channel with spatial summation (there is little spatial summation when the vibrating area is small), whereas the presence of the surround increases the 'gradient' causing stretching that it is detected at lower frequencies by the NPI (Meissner) channel.

The thresholds in Fig. 5 are shown in terms of both the vibration acceleration and the vibration displacement. While the use of acceleration is recommended in various standards associated with hand-transmitted vibration, the findings of some of the original psychophysical and physiological studies were expressed in terms of the displacement. Although the data are the same, the frequencydependence of an acceleration threshold appears very different from the frequency-dependence of the corresponding displacement threshold.

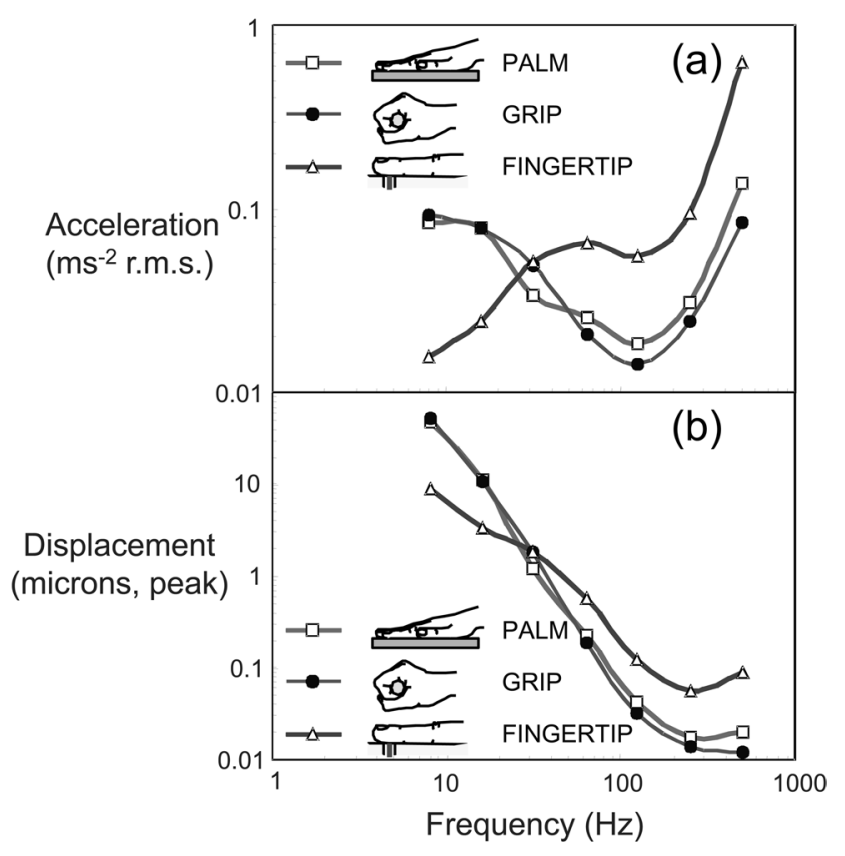

Fig. 5. Comparison of median absolute thresholds for (a) acceleration and (b) displacement between: (i) the palm pressing on a flat plate vibrating vertically, (ii) hand grip on a bar vibrating vertically, and (iii) a finger exposed to vibration from a 6-mm diameter contactor within a $10-\mathrm{mm}$ fixed circular surround (redrawn from ${ }^{7)}$ ).

The influence of a fixed surround around a small vibrating probe is well established ( ${ }^{7}$; Fig. 6). The surround determines the area of skin excited by vibration, whereas the gap between the vibrating probe and the surround, that determines the 'gradient', depends on the diameter of both the probe and the gap. The surround alters the relative sensitivity of the psychophysical channels, so it alters the shapes of threshold contours and the range of frequencies over which the different receptors determine thresholds. 


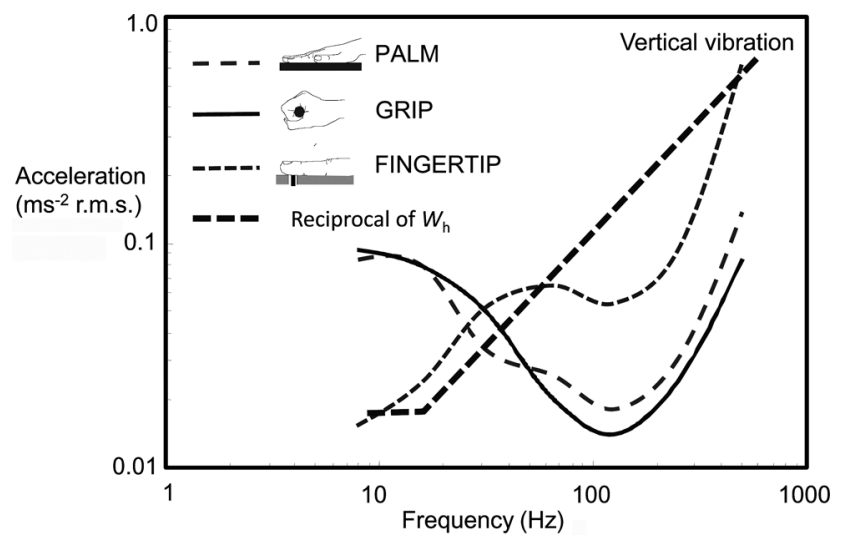

Fig. 6. Comparison of median absolute thresholds for acceleration between: (i) the palm pressing on a flat plate vibrating vertically, (ii) hand grip on a bar vibrating vertically, and (iii) a finger exposed to vibration from a $6-\mathrm{mm}$ diameter contactor within a $10-\mathrm{mm}$ fixed circular surround, and (iv) the reciprocal of frequency weighting $W_{\mathrm{h}}$ (adapted from $\left.{ }^{7}\right)$.

For example, with a large surface and no surround, the Pacinian channel may determine absolute thresholds at frequencies as low as about $20 \mathrm{~Hz}$. The introduction of a surround has two effects: (i) it reduces the area affected by vibration (reducing sensitivity in the Pacinian channel and raising Pacinian thresholds) and (ii) increasing the gradient (increasing sensitivity in the NPI channel and lowering thresholds). The Pacinian channel may then only determine thresholds at frequencies greater than about $60 \mathrm{~Hz}$. The range of frequencies determined by the different channels, which depends on various factors and will differ between individuals, changes the frequency-dependence of absolute thresholds for the perception of vibration. It is therefore difficult to state precisely either the channels mediating vibration perception or the frequency-dependence of absolute thresholds for the perception of vibration.

\section{Effect of temperature}

Various studies have shown that thresholds depend on skin temperature (e.g. ${ }^{8-10)}$ ). The greatest effect seems to be on thresholds mediated by the Pacinian channel $\left({ }^{10)}\right.$; Fig. 7). Changes in temperature therefore tend to alter the frequency-dependence of absolute thresholds, with increased sensitivity to higher frequencies with increased skin temperature.

Effect of prior exposure to hand-transmitted vibration on perception thresholds

Prior exposure to vibration can alter thresholds for the perception of vibration and other stimuli. The changes can

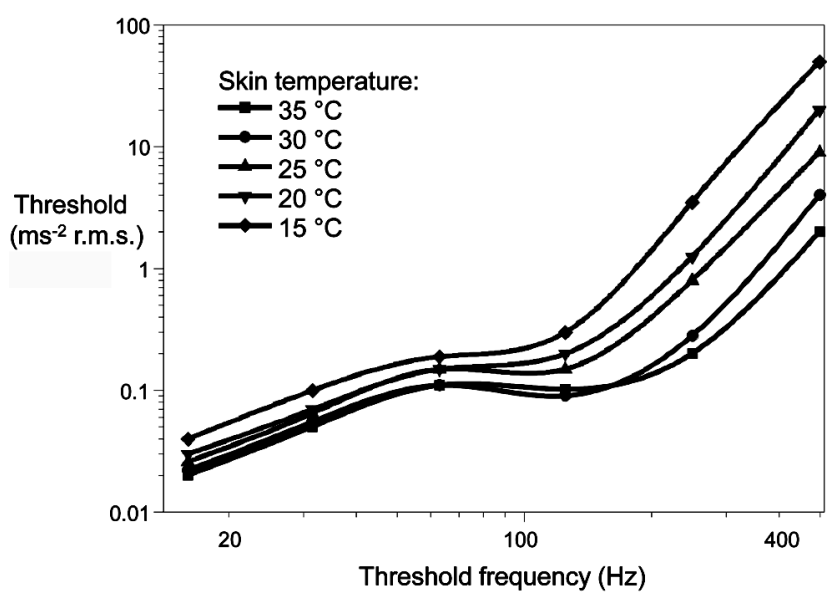

Fig. 7. Effect of temperature on frequency-dependence of absolute thresholds for the perception of vibration from a 7-mm diameter contactor with a $1.5-\mathrm{mm}$ gap to a $10-\mathrm{mm}$ fixed circular surround (redrawn from ${ }^{10)}$ ).

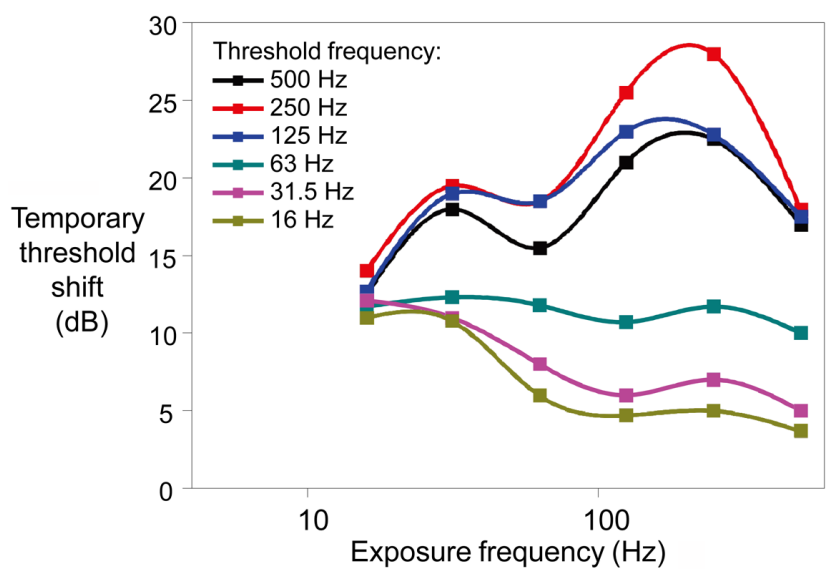

Fig. 8. Temporary shifts in vibrotactile thresholds measured at the fingertip 30-s after 5-min exposure to $20 \mathrm{~ms}^{-2}$ r.m.s. hand-transmitted vibration (mean data from 5 subjects; thresholds measured using a $7-\mathrm{mm}$ diameter probe with a $1.5-\mathrm{mm}$ gap to a $10-\mathrm{mm}$ diameter fixed circular surround). (Redrawn from ${ }^{10)}$ ).

be temporary (temporary threshold shifts, TTS) or permanent (permanent threshold shifts, PTS).

Temporary changes in vibrotactile thresholds depend on the magnitude, the frequency, and the duration of handtransmitted vibration. The shift in the threshold at any frequency is dependent on the frequency of the handtransmitted vibration: greatest elevation of low frequency thresholds is caused by low frequency vibration, whereas greatest elevation of high frequency thresholds is caused by high frequency vibration (e.g., ${ }^{10)}$; Fig. 8). It appears that the shifts in thresholds are channel-specific: a vibration that causes greater excitation within a channel tends 
to cause a greater temporary shift in the threshold of that channel. With the $20 \mathrm{~ms}^{-2}$ r.m.s. vibration used in the study shown in Fig. 8, it is likely that all channels were excited, so it is possible that the sensitivity of all four channels was elevated. However, because the P channel was most sensitive at high frequencies and the NPI channel was most sensitive at low frequencies, the data only confirm elevation of these two channels. It can be seen that thresholds at frequencies greater than $63 \mathrm{~Hz}$ were mostly affected by frequencies greater than $63 \mathrm{~Hz}$, whereas thresholds at frequencies less than $63 \mathrm{~Hz}$ were mostly affected by frequencies less than $63 \mathrm{~Hz}$.

Permanent changes in vibrotactile thresholds are used as diagnostic indicators of sensorineural damage caused by occupational exposures to hand-transmitted vibration (e.g., ${ }^{11)}$ ). Commonly, using apparatus that controls the contact conditions, thresholds are measured at two frequencies expected to be mediated by different channels (e.g., $31.5 \mathrm{~Hz}$ for NPI channel and $125 \mathrm{~Hz}$ for the P channel).

The perception of other sensory stimuli is also affected by acute exposures to hand-transmitted vibration, with perceptions of warm and cool sensations receiving most interest. Although changes in temperature perception appear useful as diagnostic indicators of peripheral sensorineural damage (e.g., ${ }^{12-14)}$ ), the changes associated with acute exposure to hand-transmitted vibration are not large ${ }^{15)}$.

\section{Vibration discomfort}

Equivalent comfort contours show how the vibration magnitude must be changed to maintain a similar subjective assessment of the strength of vibration sensations at different frequencies.

Frequency-dependence of equivalent comfort contours

The work of Miwa ${ }^{16,17)}$ had a major influence on the definition of the frequency weighting now used worldwide for quantifying the severity of hand-transmitted vibration ${ }^{18-20)}$. With ten subjects, Miwa determined 'equal sensation' contours for vertical and horizontal vibration of the hand pressed on a flat horizontal surface. He investigated the frequency range 3 to $300 \mathrm{~Hz}$ and concluded that there was no difference in the subjective response to vertical and horizontal vibration. Miwa concluded that his mean contours could be approximated by constant acceleration from 3 to $6 \mathrm{~Hz}$, constant velocity from 6 to $60 \mathrm{~Hz}$, and constant displacement from 60 to $300 \mathrm{~Hz}$ (Fig. 9).

The Japanese Association of Industrial Health sub-

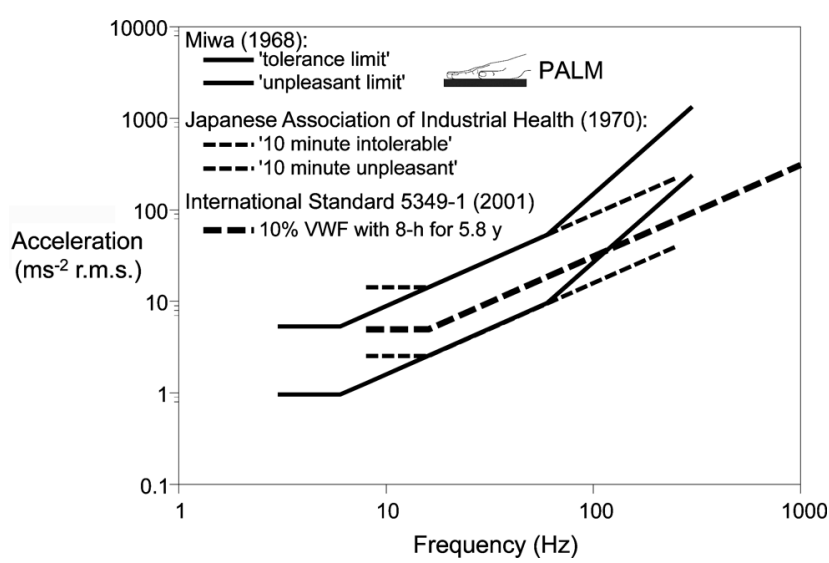

Fig. 9. The 'tolerance limit' and 'unpleasant limit' determined by Miwa ${ }^{17)}$ compared with the 10-min 'intolerable' and 10-min 'unpleasant' level defined by the Japanese Association of Industrial Health $^{21)}$, and the conditions expected to result in $10 \%$ of persons showing finger blanching after 5.8 yr exposure for 8 h per day according to ISO 5349-1:2001 ${ }^{23)}$.

sequently modified the frequency-dependence reported by Miwa to constant acceleration from 2 to $16 \mathrm{~Hz}$ and constant velocity from 16 to $300 \mathrm{~Hz}^{21)}$. This was later further modified within the ISO standards community to constant acceleration from 8 to $16 \mathrm{~Hz}$ and constant velocity from $16 \mathrm{~Hz}$ to $1000 \mathrm{~Hz}$ (Fig. 9). This first appeared as an asymptotic weighting in Draft International Standard 5349:197922). It was subsequently implemented as realisable frequency weighting $W_{\mathrm{h}}$ and appears in current standards (e.g., ISO 5349-1:200123); ISO 8041:2005 ${ }^{24)}$ ).

It will be appreciated that although the frequency weighting $W_{\mathrm{h}}$ was stimulated by the work of Miwa it cannot be said to have the same frequency-dependence as his experimental data: he only studied frequencies in the range 3 to $300 \mathrm{~Hz}$, whereas $W_{\mathrm{h}}$ extends from approximately 8 to $1000 \mathrm{~Hz}$ and, even over the range 3 to $300 \mathrm{~Hz}$, the frequency-dependence is very different (Fig. 9).

In the 45 years since the pioneering work of Miwa, other equivalent comfort contours have been developed (e.g. ${ }^{25-27)}$ ) and show that other factors affect the frequency-dependence of the discomfort caused by handtransmitted vibration.

Effect of vibration magnitude

The frequency-dependence of the equivalent contours developed by Miwa is very different from the frequencydependence of the absolute threshold for the perception of hand-transmitted vibration. Studies of equivalent comfort over a range of vibration magnitudes show that the frequency-dependence changes as the vibration magnitude 


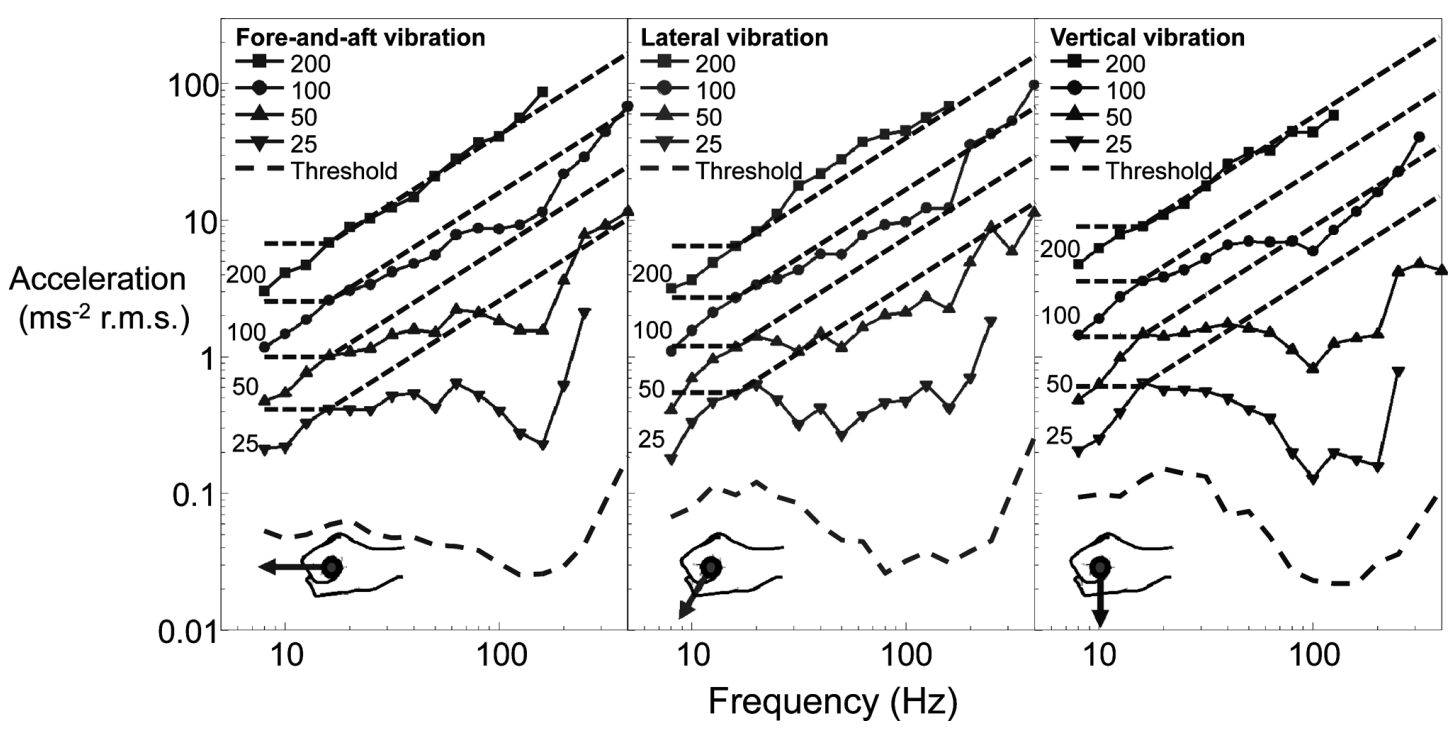

Fig. 10. Equivalent comfort contours for sensation magnitudes from 25 to 200 relative to a sensation magnitude of 100 for a vibration magnitude of $5.0 \mathrm{~ms}^{-2}$ r.m.s. at $50 \mathrm{~Hz}$ and median absolute threshold for perception of fore-and-aft, lateral, and vertical vibration from a cylindrical handle. Frequency weightings represented by reciprocal of $W_{\mathrm{h}}$ drawn to coincide with experimental equivalent comfort contours at $16 \mathrm{~Hz}$. (Adapted from ${ }^{26,48)}$ ).

increases above the absolute threshold for perception.

For subjects gripping a cylindrical handle, Morioka and Griffin (2006) investigated perception thresholds (in the frequency range 8 to $315 \mathrm{~Hz}$ ) and the strength of sensation caused by each of the three axes of hand-transmitted vibration (in the frequency range 8 to $400 \mathrm{~Hz}$ ) at vibration magnitudes from threshold to those associated with discomfort and injury (Fig. 10). In all three axes, acceleration thresholds for the perception of vibration showed a Ushaped frequency-dependence with greatest sensitivity around 80 to $160 \mathrm{~Hz}$. At supra-threshold levels, the frequency-dependence of the equivalent comfort contours in each of the three axes was highly dependent on vibration magnitude. With increasing vibration magnitude, equivalent sensation approximated towards constant velocity, whereas with decreasing magnitudes the sensation became increasingly similar to the absolute perception threshold.

The magnitude-dependence of equivalent comfort contours suggests mediation of the perception of vibration by different channels at different vibration magnitudes. The results also imply that no single linear frequency weighting can provide accurate predictions of subjective judgments of discomfort caused by hand-transmitted vibration: the appropriate frequency weighting depends on the magnitude of vibration.

There is some evidence that equivalent comfort contours can be influenced by grip force, with increased sensitivity at high frequencies when increasing grip force with low magnitude vibration ${ }^{27)}$. Hand posture can also be expected to have an effect, especially at lower frequencies where the transmission of vibration to the torso can be reduced by bending of the elbow.

\section{Acute Vascular Responses to Vibration}

Regular and prolonged exposures to hand-transmitted vibration in a wide variety of occupations give rise to permanent vascular changes. In the condition known as vibration-induced white finger, 'attacks' of finger whiteness may be provoked by exposure to cold: the underlying disorder is caused by exposure to vibration, but an 'attack' of finger blanching is most often caused by cold. Vibrationinduced white finger may therefore be characterised by the peripheral circulation showing an abnormal response to cold. Whereas the normal response to cold is a reduction in finger blood flow, those affected by vibration-induced white finger show a cessation of blood flow in all, or part, of a finger during an attack. The mechanisms involved in the regulation of finger blood flow are complex and not fully understood. The pathogenesis of vibration-induced white finger is also not understood.

A single exposure to hand-transmitted vibration does not cause vibration-induced white finger, but it is of interest that finger blood flow is reduced during and following any single exposure to hand-transmitted vibration. The extent to which this acute response reflects the mechanisms 


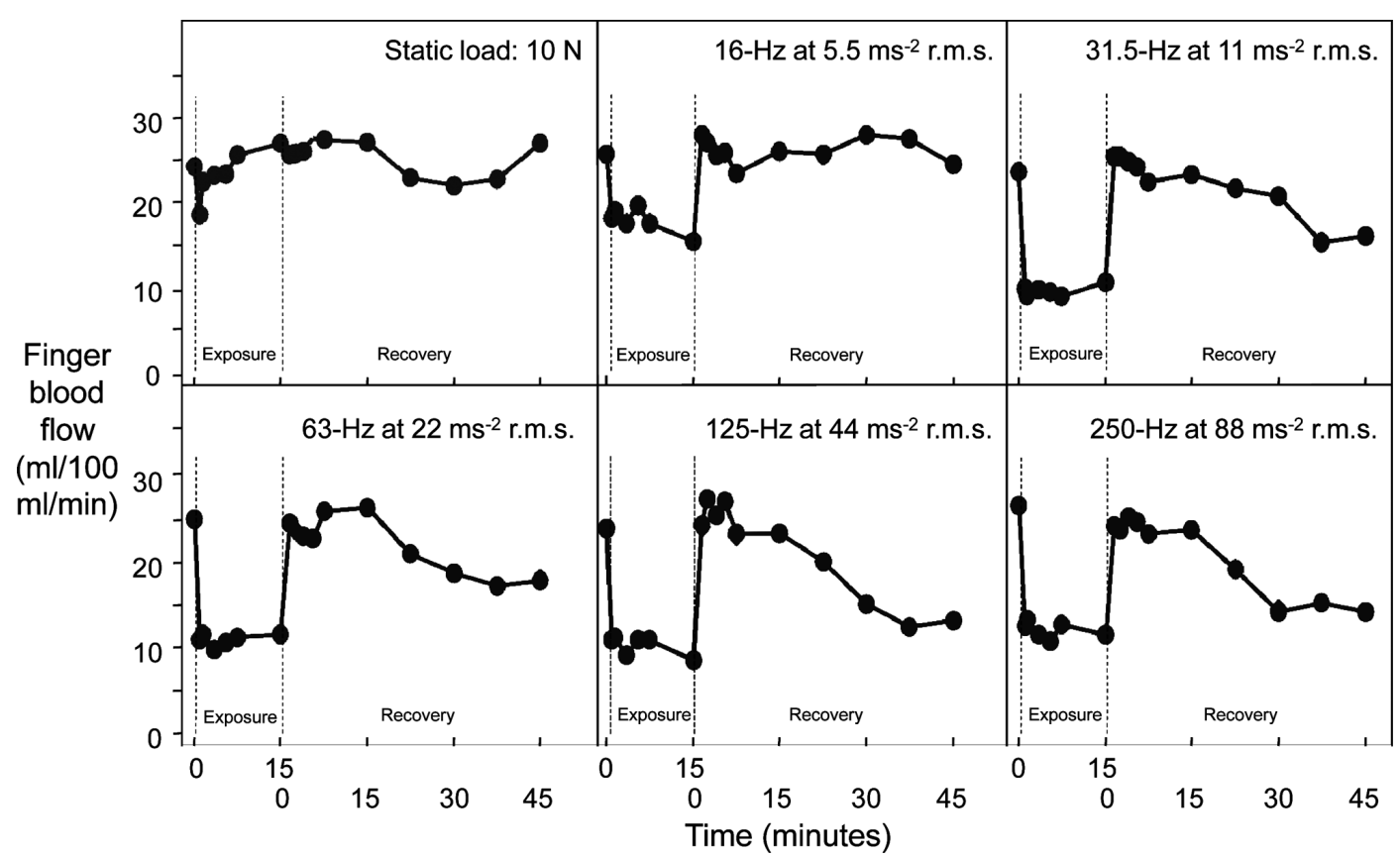

Fig. 11. Finger blood flow before, during, and after 15-minute exposures to static load (contact force $10 \mathrm{~N}$ ) or vibration with different combinations of frequencies and unweighted acceleration magnitudes but the same frequencyweighted acceleration (5.5 $\mathrm{ms}^{-2}$ r.m.s.) according to ISO 5349-1:2001 (mean values from 10 males) (adapted from ${ }^{34)}$ ).

involved in the chronic changes associated with vibrationinduced white finger has yet to be unravelled. However, the acute changes in finger blood flow can be large and they have attracted interest in how they depend on the characteristics of vibration, including the frequency of vibration.

Early studies of the effects of the frequency of vibration on acute changes in finger blood flow used vibration stimuli having either the same acceleration or the same displacement at different frequencies ${ }^{28-32)}$. Different responses were generally obtained at different frequencies, suggesting that neither the acceleration nor the displacement would predict the changes, but the conditions did not include vibrations with the same velocity (consistent with the $W_{\mathrm{h}}$ frequency weighting between 16 and $1,000 \mathrm{~Hz}$ ) or determine the effects of vibration magnitude (allowing the influence of differing weightings to be determined).

A series of experimental studies involving collaboration between the Universities of Trieste in Italy and Southampton in the UK has used finger plethysmography to measure changes in finger blood flow during and following exposure to vibration applied to the finger or hand and investigate how vasoconstriction depends on the frequency of vibration ${ }^{33-35)}$, the magnitude of vibration ${ }^{33}, 36,37$ ), the duration of vibration $^{37,38)}$, intermittent vibration ${ }^{39)}$, and the force applied by the hand or finger ${ }^{35,40)}$. Related stud- ies have further investigated the effects of the frequency of vibration ${ }^{41)}$, the magnitude of vibration ${ }^{42)}$, temperature $^{43)}$, and individual variability ${ }^{42,44)}$. The dependence of vibration-induced vasoconstriction on the frequency of vibration is summarised below.

Dependence of vibration-induced vasoconstriction on the frequency and magnitude of hand-transmitted vibration

Changes in finger blood flow caused by 15-min exposures to hand-transmitted vibration at 16, 31.5, 63, 125 and $250 \mathrm{~Hz}$ were investigated using the same vibration velocity at each frequency, so that the frequency-weighted acceleration was always $5.5 \mathrm{~ms}^{-2}$ r.m.s. (when using frequency weighting $\left.W_{\mathrm{h}}\right)^{34)}$. In the vibrated right finger, vibration at frequencies from 31.5 to $250 \mathrm{~Hz}$ provoked greater reductions in FBF than with either $16-\mathrm{Hz}$ vibration or a static load without vibration (Fig. 11). There were also reductions in finger blood flow in a non-vibrated left finger. In fingers on both hands there were reductions in blood flow after cessation of vibration at frequencies from 31.5 to $250 \mathrm{~Hz}$, with greater reductions at higher frequencies. It was concluded that the frequency weighting in current standards tends to overestimate the vasoconstriction associated with acute exposures to vibration at frequencies around $16 \mathrm{~Hz}$ (Fig. 12).

Various studies have shown that the vasoconstriction 


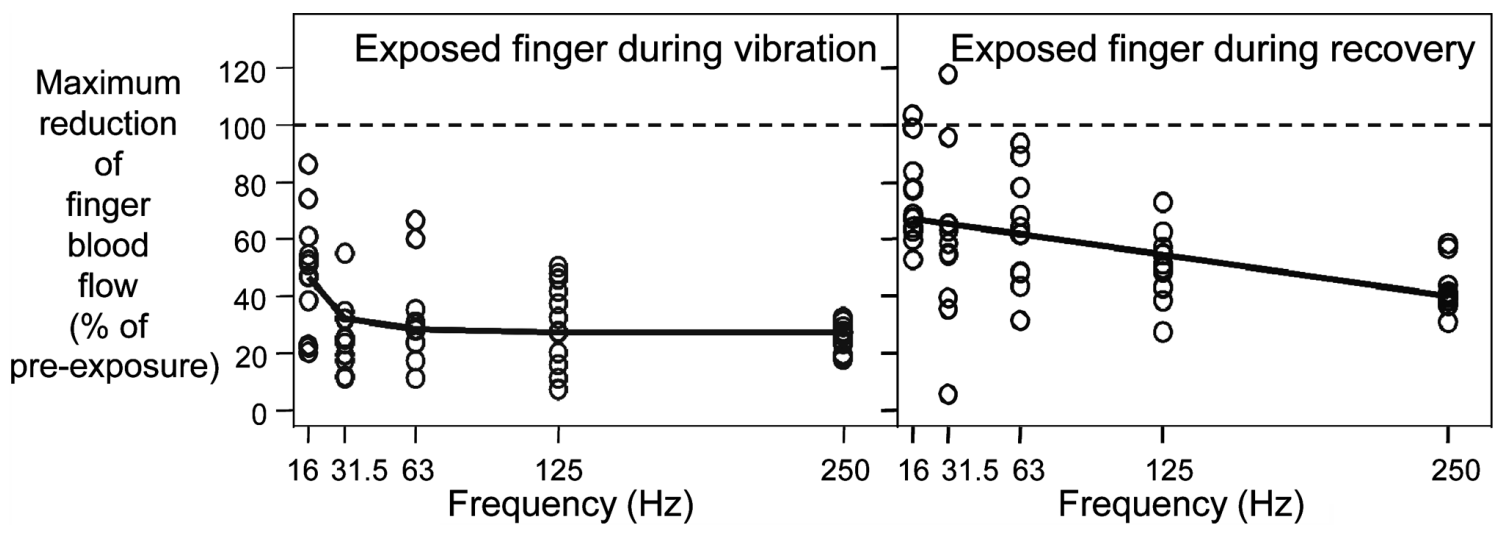

Fig. 12. Dependence on vibration frequency of the maximum reduction in finger blood flow (expressed as a percentage of pre-exposure values) during, and $45 \mathrm{~min}$ after, 15-min exposures to a frequency-weighted acceleration of $5.5 \mathrm{~ms}^{-2}$ r.m.s. (individual data from 10 male subjects) (adapted from ${ }^{34)}$ ).

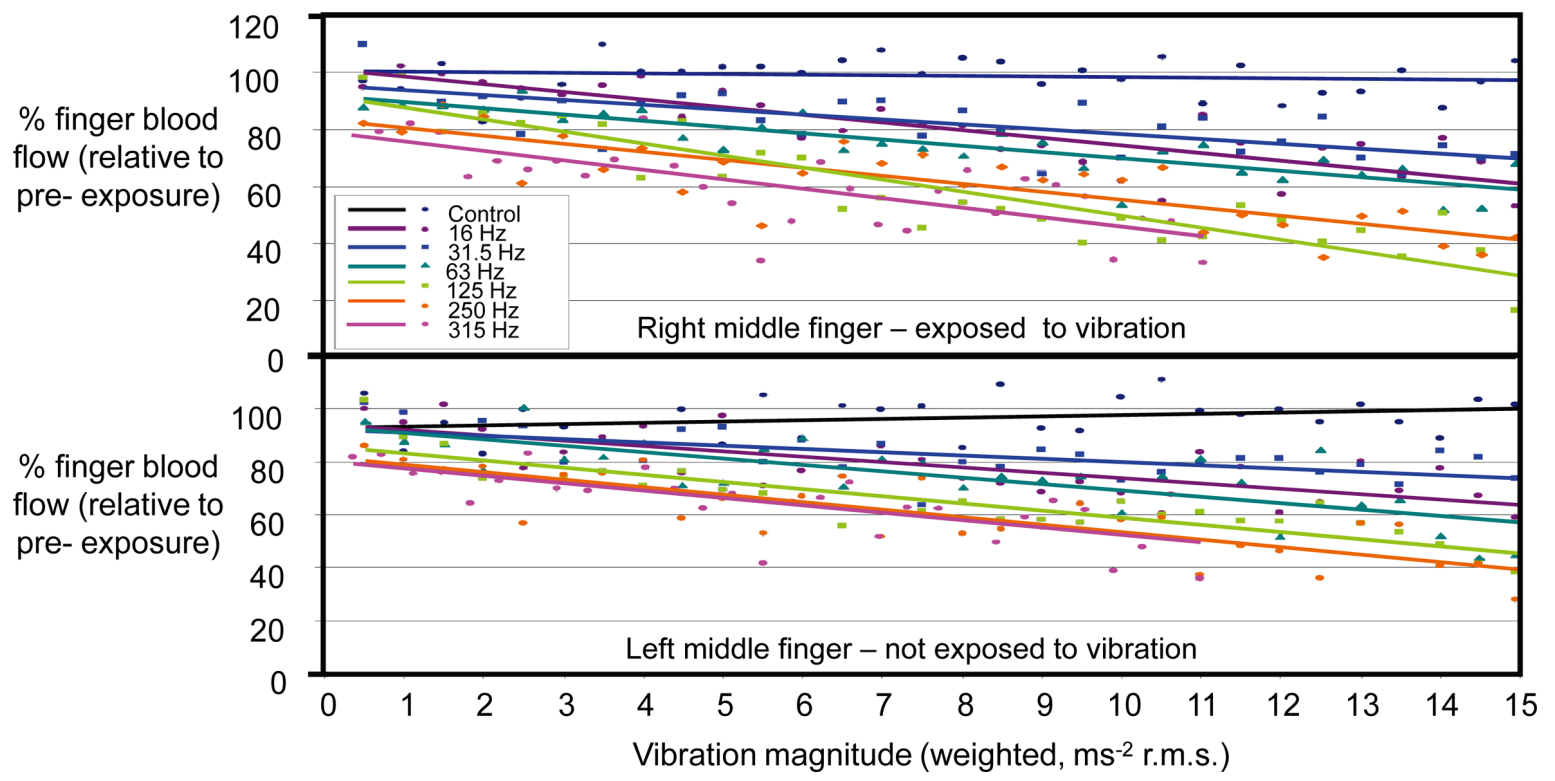

Fig. 13. Median percentage changes in finger blood flow (\%FBF) in the exposed right middle finger and the non-exposed left middle finger as vibration increased from 0 to $15 \mathrm{~ms}^{-2}$ r.m.s. (frequency-weighted) at 16, 31.5, 63, 125, $250 \mathrm{~Hz}\left(0\right.$ to $11 \mathrm{~ms} \mathrm{~s}^{-2} \mathrm{r}$.m.s. at $315 \mathrm{~Hz}$ ) and during a control condition without vibration over the same 30-min period. Data from 12 male subjects with linear least squares regressions also shown. (Adapted from ${ }^{41)}$ ).

during exposure to vibration increases with increases in the magnitude of vibration but has little dependence on the duration of vibration. By progressively increasing the magnitude of vibration from 0 to $15 \mathrm{~ms}^{-2}$ r.m.s. (frequencyweighted) over 30 minutes ( 0 to $11 \mathrm{~ms}^{-2}$ r.m.s. at $315 \mathrm{~Hz}$ ), the magnitude-dependence of the vasoconstriction at 16 , $31.5,63,125,250$, and $315 \mathrm{~Hz}$ has been investigated ${ }^{41)}$. In fingers exposed to vibration and in fingers not exposed to vibration, blood flow reduced with increasing vibration magnitude (Fig. 13). At the same frequency-weighted acceleration according to current standards, finger blood flow was dependent on the vibration frequency, with vibration at 125,250 , and $315 \mathrm{~Hz}$ causing the greatest reductions in finger blood flow. With vibration at $250 \mathrm{~Hz}$ and $315 \mathrm{~Hz}$, frequency-weighted accelerations less than $1.0 \mathrm{~ms}^{-2}$ r.m.s. reduced finger blood flow, whereas greater weighted acceleration magnitudes were required at the lower frequencies. After the cessation of vibration, finger blood flow in exposed and unexposed fingers also depended on the frequency of vibration, with greater vasoconstriction after exposure to the higher frequencies (Fig. 14). Vibration of one hand produced a similar vasoconstriction in fingers on 


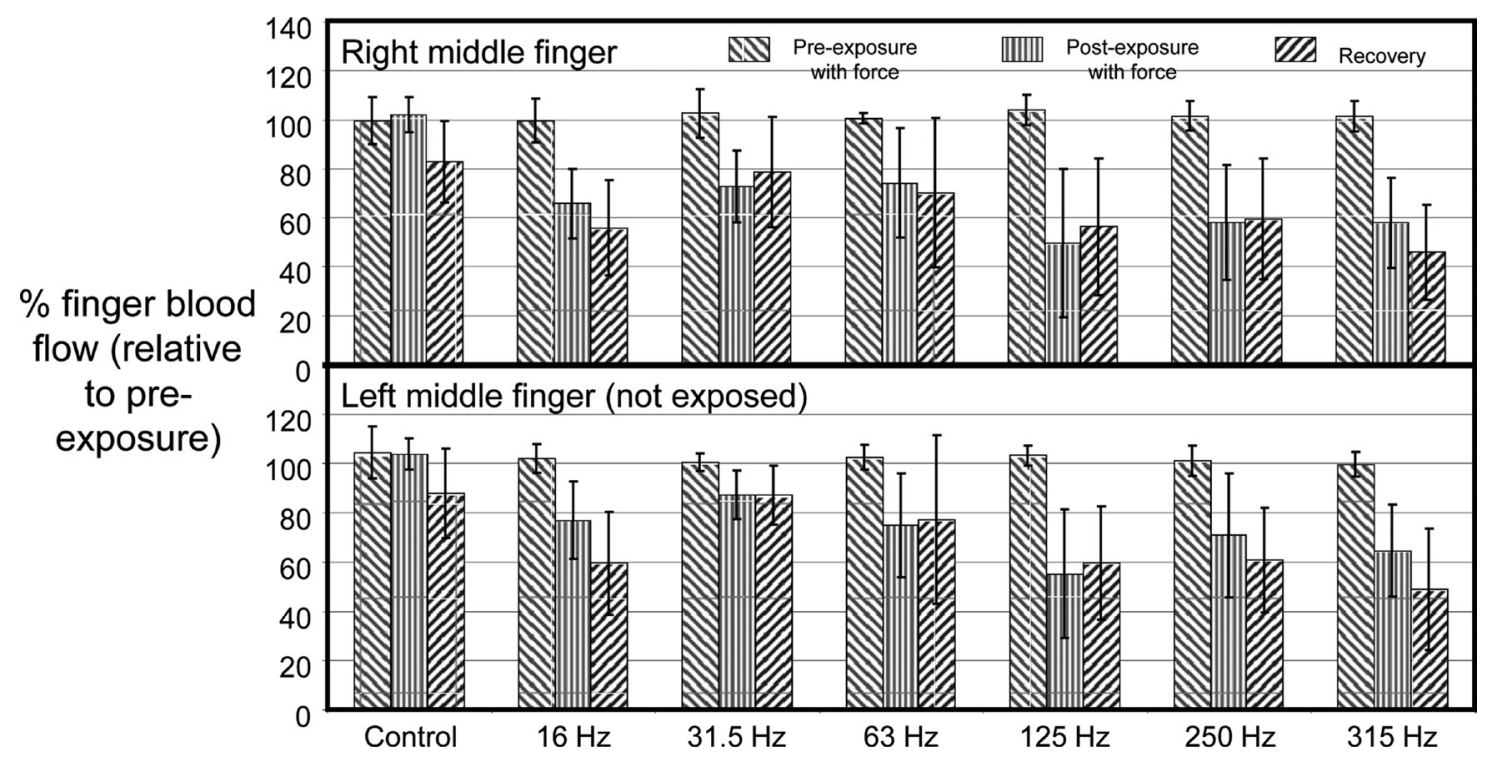

Fig. 14. Percentage changes in finger blood flow in the exposed right middle finger and the non-exposed left middle finger associated with: (i) pre-exposure application of force, (ii) post-exposure application of force, (iii) recovery. Medians and inter-quartile ranges from 12 subjects during a control condition and sessions with vibration at 16, 31.5, 63, 125, 250 and 315 Hz. (Adapted from ${ }^{41)}$ ).

the exposed and the unexposed hand, suggesting a centrally mediated response. The findings of this study also show that finger blood flow is reduced by vibration magnitudes much lower than those on very many powered hand tools.

A relation between vibration-induced reductions in finger blood flow and vibrotactile perception thresholds mediated by the Pacinian channel has been reported ${ }^{42)}$. With 40 subjects ( 20 male and 20 female) they measured absolute thresholds for the perception of $125-\mathrm{Hz}$ vibration applied by a $6-\mathrm{mm}$ diameter probe (within a $10-\mathrm{mm}$ diameter surround) to the thenar eminence of the right hand and, separately, any changes in finger blood flow when $125-\mathrm{Hz}$ vibration was applied by the same probe at 0.5 and $1.5 \mathrm{~ms}^{-2}$ r.m.s. (unweighted). These magnitudes were chosen because they were expected to be below the thresholds of some subjects but above the thresholds of others. When the vibration magnitude was greater than individual vibration thresholds, changes in finger blood flow were correlated with thresholds (with both 0.5 and $1.5 \mathrm{~ms}^{-2}$ r.m.s. vibration): subjects with lower thresholds showed greater reductions in finger blood flow (Fig. 15). Females had lower vibrotactile thresholds and showed greater vibration-induced reductions in finger blood flow. It was concluded that mechanoreceptors responsible for mediating vibration perception are involved in the vascular response to vibration.

Increases in the magnitude of vibration tend to increase vasoconstriction, both during and after exposure to vibra- tion, and in fingers exposed to vibration and in fingers not exposed to vibration. However, the relation between the magnitude of vibration and the vasoconstriction can only be approximated by a linear relation over a restricted range of vibration magnitudes: it seems that vasoconstriction does not occur below some threshold magnitude, and finger blood flow cannot fall below zero. The inevitable non-linearity in the relation between vibration magnitude and finger blood flow means that the dependence of vasoconstriction on the frequency of vibration must depend on the magnitude of vibration. This may be discerned from Fig. 13.

\section{Effect of other factors}

There are no known systematic studies of how the vasoconstriction caused by different frequencies of vibration combine, although such information is needed if a weighting is used to evaluate the severity of vibration containing more than a single frequency.

There are no known systematic studies of how finger blood flow depends on the direction of vibration, or how the effects caused by different directions combine. Such information is needed if weightings are to be used to predict the severity of multi-axis vibration.

The changes in vasoconstriction induced by acute exposures to hand-transmitted vibration are complex and interact with other factors that can have a large influence on finger blood flow. For example, the absolute reduction 


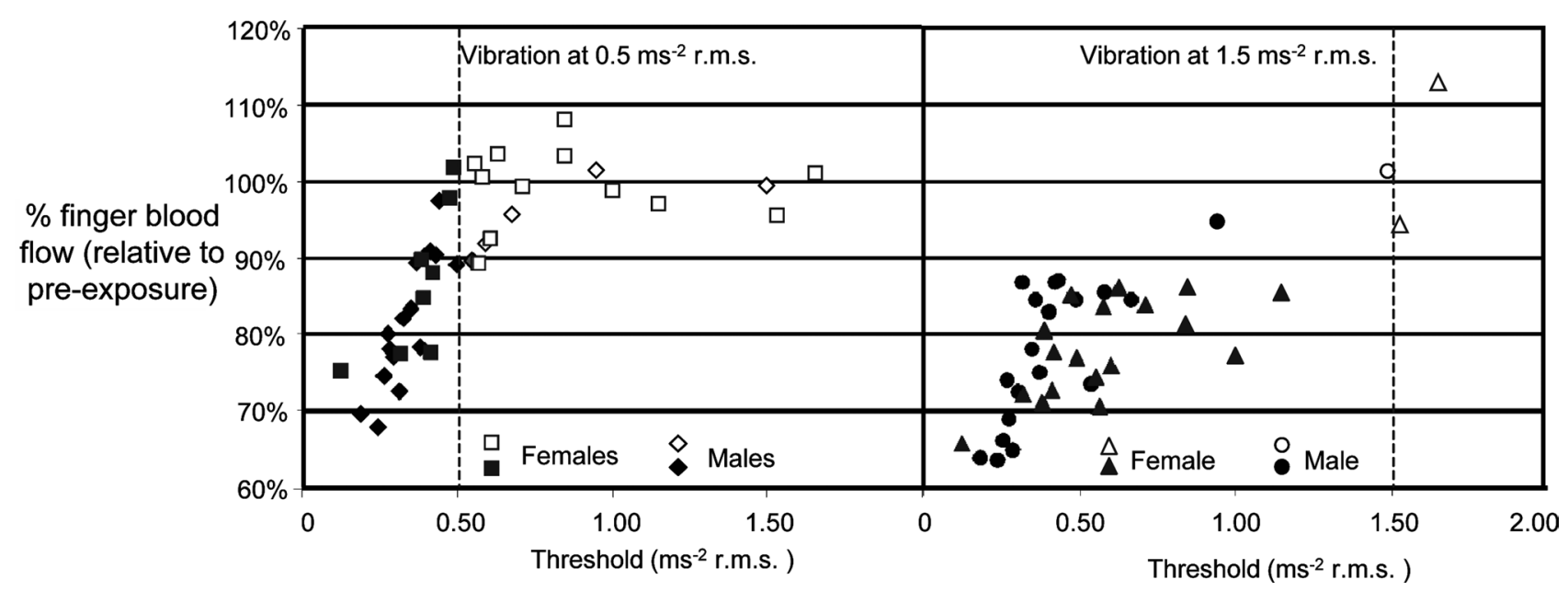

Fig. 15. Relation between vibrotactile perception thresholds and FBF\% in the middle finger of the right (exposed) hand during exposure to $125-\mathrm{Hz}$ vibration at $0.5 \mathrm{~ms}^{-2}$ r.m.s. and $1.5 \mathrm{~ms}^{-2}$ r.m.s. in male and female subjects. Open symbols: subjects with a perception threshold higher than the vibration magnitude of $0.5 \mathrm{~ms}^{-2}$ r.m.s. or $1.5 \mathrm{~ms}^{-2}$ r.m.s.; solid symbols: subjects with a perception threshold lower than the vibration magnitude of $0.5 \mathrm{~ms}^{-2}$ r.m.s. or $1.5 \mathrm{~ms}^{-2}$ r.m.s. (Adapted from ${ }^{42}$ ).

in finger blood flow is greater when the temperature is greater, but the percentage reduction in finger blood flow relative to finger blood flow before vibration exposure is similar ${ }^{43)}$. Those with greater finger blood flow before vibration tend to have greater blood flow during vibration, and those with greater finger blood flow with one temperature tend to have greater blood flow with another temperature $^{43)}$.

Vibration cannot be applied to the body without also applying a force, which may itself cause a change of finger blood flow. Modest levels of force applied by a finger can have a large effect on finger blood flow, possibly due to the constriction of local blood vessels ${ }^{35}$, 40). Similarly, with force applied by the palm of the hand, blood flow may be reduced in fingers on the exposed hand, probably due to compression of parts of the vascular system serving the fingers ${ }^{12)}$. There is some evidence that force may also reduce finger blood flow in the contralateral hand, possibly due to a central sympathetic effect ${ }^{44)}$.

There is no evidence indicating whether the potentially large effects of temperature and force have different effects with different frequencies of vibration. However, different types of tool tend to be dominated by different frequencies of vibration, and different types of tool can be associated with different temperatures and different contact forces. A frequency weighting based solely on laboratory studies with controlled temperatures, forces, and other factors, might allow predictions of the percentage changes in finger blood flow caused by vibration, but other factors need to be considered when predicting the absolute finger blood flow that will occur when using a range of tools with a range of finger temperatures, contact forces, metabolic activities, and other factors.

\section{Discussion}

Although many studies have explored human responses to hand-transmitted vibration it is disappointing that so few have systematically explored how the psychophysical and physiological responses depend on the frequency of vibration. With psychophysical and physiological responses also highly dependent on other variables (e.g., the magnitude of vibration and the contact conditions) it is challenging to provide a coherent view of the current state of understanding. It has been necessary to focus on studies where frequency has been an independent variable within experiments, and where the conditions in different studies can be compared, and this has resulted in references to an uncomfortable number of studies with which the author is associated. There is scope for experimental studies to advance understanding of how the frequency of vibration determines psychophysical and physiological responses to hand-transmitted vibration over a wider range of conditions.

Knowledge of the extent to which a response varies with the frequency of vibration is insufficient to define a frequency weighting for evaluating the severity of handtransmitted vibration. It must be known whether the weighting is appropriate at all magnitudes (i.e., the 'linearity' of the response), and appropriate in all directions, for 


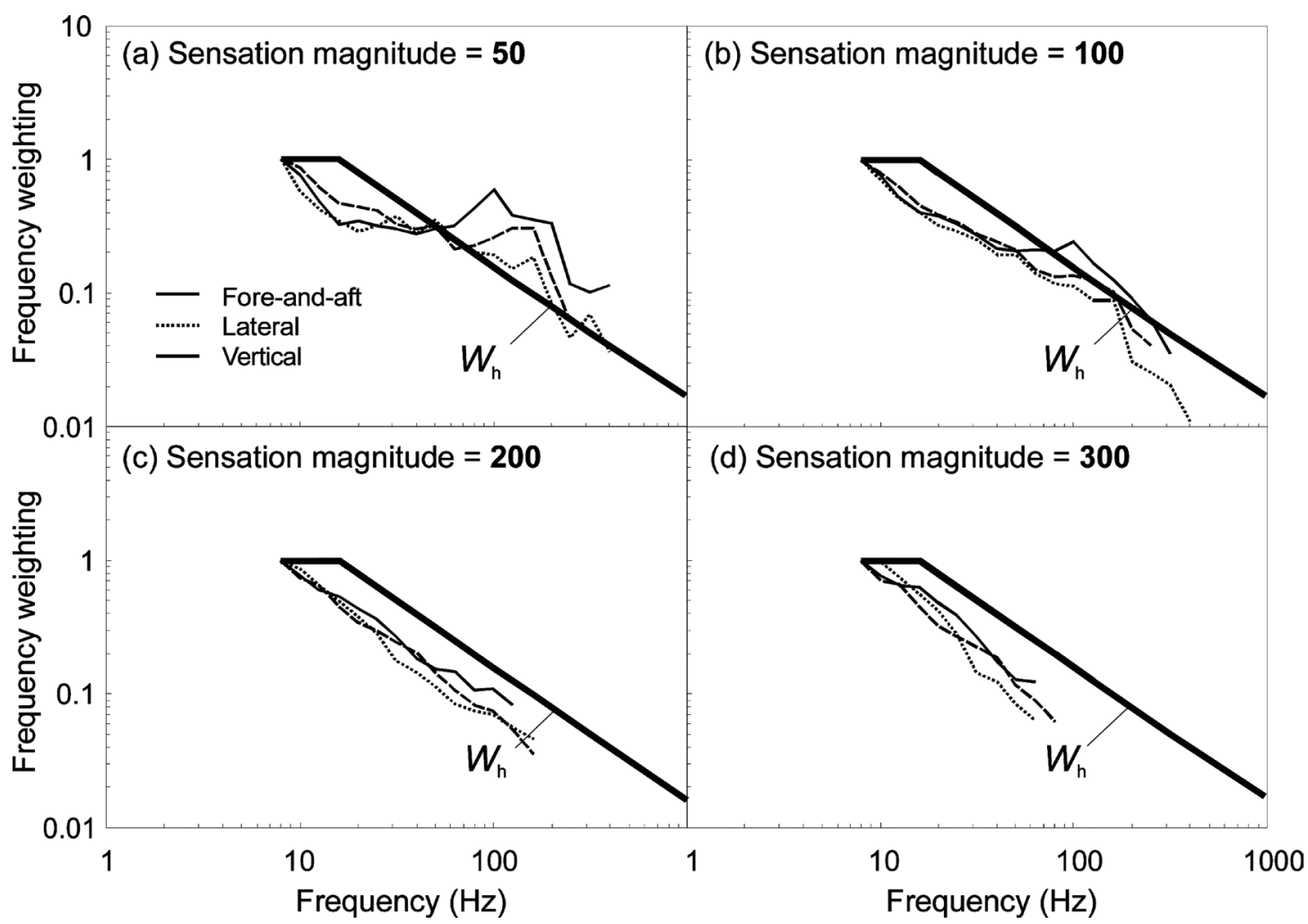

Fig. 16. Comparisons of frequency weighting $W_{\mathrm{h}}$ with the frequency-dependence of equivalent comfort contours determined experimentally when gripping a cylindrical handle at four subjective magnitudes: (a) 50, (b) 100, (c) 200, and (d) 300 (where a sensation magnitude of 100 is equivalent to the discomfort produced by $5.0 \mathrm{~ms}^{-2}$ r.m.s. at $50 \mathrm{~Hz}$ ): - - - - foreand-aft, ---- lateral, and — vertical $^{26)}$.

all durations, and for all disorders. It is also necessary to know, or assume, how vibrations of different frequencies (and directions and durations) should be combined.

From the experimental studies it may be concluded that there is much that is not known and rather little that is fully understood. Nevertheless, the findings are sufficient to see that psychophysical and physiological responses have characteristic frequency-dependencies that are non-linear - the dependence of a response on the frequency of vibration varies with the magnitude of vibration. It follows that the dependence of the psychophysical and physiological responses to vibration cannot be predicted with accuracy by using any single simple frequency weighting.

It is clearly not wise to predict both thresholds for the perception of hand-transmitted vibration and vibration discomfort using the same frequency weighting (Fig. 10). If interest is restricted to a range of vibration magnitudes, useful predictions of the discomfort produced by handtransmitted vibration may be possible using a single frequency weighting. The same frequency weighting might be used for all three directions of translational vibration. For frequency-weighted vibration magnitudes in the ap- proximate range 1.6 to $4.8 \mathrm{~ms}^{-2}$ r.m.s., it might be casually concluded that the frequency weighting $W_{\mathrm{h}}$ is reasonable (Fig. 15). However, the applicability of weighting $W_{\mathrm{h}}$ has not been investigated at frequencies greater than about $400 \mathrm{~Hz}$. At frequencies greater than about $400 \mathrm{~Hz}$, a vibrating handle generates high levels of noise and so subjective assessments of vibration may seem irrelevant. Even over the frequency range 8 to $400 \mathrm{~Hz}$ and with magnitudes in the range 1.6 to $4.8 \mathrm{~ms}^{-2}$ r.m.s. (weighted), it seems that weighting $W_{\mathrm{h}}$ may easily be in error by a factor of 2 (Fig. 16). Greater 'errors' can be expected if $W_{\mathrm{h}}$ is used over a wider range of frequencies, or over a wider range of magnitudes, or with a range of grips and postures.

Investigations of the frequency-dependence of the vasoconstriction caused by hand-transmitted vibration seem to conclude that vibration magnitudes with the same frequency-weighted acceleration do not produce the same vasoconstriction, either during exposure to vibration or after exposure to vibration. If frequency weighting $W_{\mathrm{h}}$ was appropriate, all regression lines representing the average vasoconstriction caused by vibration at $16,31.5,63,125$, 250, and $315 \mathrm{~Hz}$ in Fig. 12 would be coincident, whereas 
frequencies in the range 16 to $63 \mathrm{~Hz}$ produced less vasoconstriction than the higher frequencies. It would not seem appropriate to expect the same frequency-dependence in all studies, because the relation between vibration magnitude and the percentage reduction in finger blood flow is inevitably non-linear and the manner in which vasoconstriction depends on the vibration frequency is likely to be dependent on the contact area, contact force, temperature, etc. The frequency-dependence of vasoconstriction does not seem to be predictable from either equivalent comfort contours or absolute thresholds for vibration perception when these responses are mediated by differing receptors at different frequencies. Without a more sure-footed understanding of the mechanisms involved in vibration-induced vasoconstriction it would be unwise to make a blind speculation on how it can be predicted. However, the results suggest that frequency weighting $W_{\mathrm{h}}$ underestimates the vasoconstriction caused by vibration at frequencies between about 63 and $315 \mathrm{~Hz}$ relative to the vasoconstriction caused by lower frequencies. Between 63 and $315 \mathrm{~Hz}$, vasoconstriction might be better predicted by unweighted acceleration, or by a weighting based on the threshold for the perception of vibration. Basic research must provide a foundation for a model of the relevant mechanisms before confident predictions of the frequency-dependence of the vibration-induced vasoconstriction can be offered.

It might be assumed that an appropriate frequency weighting for predicting human response to hand-transmitted vibration exists and that it merely awaits discovery (in scientific communities) or definition and agreement (in standardisation communities). It is more likely that the physiological and psychophysical responses to handtransmitted vibration are varied, complex, and non-linear, defying simple precise definition.

It should not be forgotten that there is always large variability in responses to vibration, both within and between individuals. Vibrotactile thresholds, equivalent comfort contours, and finger blood flow differ greatly between people. The responses most often reported from experiments are averages obtained from a small group of fit individuals. The people who suffer first from a disorder caused by hand-transmitted vibration should not be expected to have 'average sensitivity', and so may have characteristics different from the average, including a different frequency-dependence. Furthermore, an individual can greatly change the transmission of vibration to the fingers and the hand by varying the contact location and contact force: the variation in vibration transmission between contact conditions and postures can be great, suggesting different frequency-dependence in differing conditions ${ }^{45)}$. Although a single frequency weighting is required for unified methods of reporting vibration exposures, it would be delusionary to assume that any single frequency weighting will ever provide accurate predictions of vibration-induced injuries.

Ideally, a frequency weighting should be associated with a defined response, and defined using evidence of the frequency-dependence of that response and how it depends on the magnitude, direction, and duration of vibration, and contact with the source of the vibration. Without defined foundations and scope, a weighting is not meaningful and can be misapplied ${ }^{18,46)}$. Although frequency weighting $W_{\mathrm{h}}$ requires the measurement of vibration at frequencies up to $1,000 \mathrm{~Hz}$ (which is challenging and often not achieved accurately), frequencies greater than about $400 \mathrm{~Hz}$ generally have little effect the weighted value ${ }^{19)}$. The original studies on which the weighting was based were limited to $300 \mathrm{~Hz}$ 16,17 , with an ISO committee extrapolating the range to $1,000 \mathrm{~Hz}$, assuming a velocity response. From his experimental data, Miwa suggested a displacement response from 60 to $300 \mathrm{~Hz}$, so an extrapolation of his data would have resulted in even less sensitivity to higher frequencies than implied by weighting $W_{\mathrm{h}}$. The requirement to include the higher frequencies in measures of vibration severity is based on the unproven assumption that these higher frequencies are harmful and that their harm is predicted by the velocity of the vibration. Vibration at frequencies greater than $400 \mathrm{~Hz}$ may be assumed to be capable of causing injury, but experimental studies with humans do not yet seem to suggest a frequency-dependence appropriate for predicting subjective or physiological responses at frequencies greater than about $400 \mathrm{~Hz}$.

Within the range over which a frequency weighting is defined it is necessary to be specific on the weighting required at each frequency. So that different measuring instrumentation provides similar values, the weighting must be defined precisely with narrow tolerances. In contrast, experimental studies show that human responses to different frequencies vary greatly according to the response that is measured, the vibration magnitude, the contact conditions, the individual sensitivity, etc. The variability in the actual human response may be more than an order of magnitude greater than the variability tolerated in instrumentation. This mismatch of accuracies is confusing unless it is made clear that accurate measurement and evaluation of a vibration exposure does not imply accurate assessment of the risks arising from the exposure. The findings of experimental studies might be used to estimate, 
and standardise the reporting of, the uncertainty associated with predictions of vibration severity, so that it is not mistakenly assumed that vibration exposures a little below a boundary are safe and exposures a little above a boundary are unsafe. It is clear that there is, and always will be, a wide zone of uncertainty over which the risks progressively increase.

Amid the doubt and uncertainty it might be decided that it is better to define the 'wrong frequency weighting' than to define no frequency weighting. This may be true for 'vibration evaluation' (that allows the reporting of an exposure), but it is potential dangerous for 'vibration assessment' (that judges the acceptability of an exposure and the need for action). Prolonged widespread use of an inappropriate frequency weighting may be expected to result in reductions in the weighted accelerations on tools (due to design changes) and reductions in the equivalent daily exposures to hand-transmitted vibration (due to restrictions at work). The implied reductions in risk may be real or illusory. Lower weighted values are very likely to indicate reduced risk if the reduction is achieved without changing the vibration spectrum. However, if the reduction in weighted acceleration is achieved by changing the vibration frequency, lower values of acceleration determined with an inappropriate frequency weighting may not reduce the risk and could increase the risk. The benefits from means of changing the vibration transmitted to the hand (e.g., the use of vibration isolation, including gloves) may be wrongly assessed when using an inappropriate weighting, resulting in both false claims and missed opportunities $^{47)}$.

It may be concluded that human responses to handtransmitted vibration are far more varied, and more interesting, than implied by a single frequency weighting. There are major challenges when applying the currently incomplete understanding and in contributing to new and improved understanding.

\section{Conclusions}

There is experimental evidence that psychophysical and physiological responses to hand-transmitted vibration are both complex and interesting, but there is limited understanding of the mechanisms underlying the frequencydependence of responses. Without admitting the uncertainties, it would be misleading to advocate any single frequency weighting for predicting the effects of handtransmitted vibration.

Although much is not yet understood it is clear that the frequency-dependence of absolute thresholds for the perception of hand-transmitted vibration differs from the frequency-dependence of discomfort caused by vibration at greater magnitudes. Studies of the vasoconstriction caused by acute exposures to hand-transmitted vibration suggest that the currently standardised frequency weighting (i.e., frequency weighting $W_{\mathrm{h}}$ ) underestimates the vasoconstriction caused by frequencies greater than about $63 \mathrm{~Hz}$ relative to the vasoconstriction caused by frequencies less than $63 \mathrm{~Hz}$.

The frequency range over which there is some understanding of the psychophysical and physiological responses to vibration does not extend to the full range of frequencies covered by frequency weighting $W_{\mathrm{h}}$ : there is little experimental evidence of response to frequencies greater than about $400 \mathrm{~Hz}$.

It is concluded that any proposal for a frequency weighting should be accompanied by evidence of the foundations on which it is based and a scope of application. The limitations and uncertainties associated with a frequency weighting are no less important than the definition of the weighting.

\section{References}

1) Johansson RS, Vallbo ÅB (1983) Tactile sensory coding in the glabrous skin of the human hand. Trends Neurosci $\mathbf{6}$, 27-32. [CrossRef]

2) Vallbo $\AA \mathrm{B}$, Johansson RS (1984) Properties of cutaneous mechanoreceptors in the human hand related to touch sensation. Hum Neurobiol 3, 3-14. [Medline]

3) Iggo A, Ogawa H (1977) Correlative physiological and morphological studies of rapidly adapting mechanoreceptors in cat's glabrous skin. J Physiol 266, 275-96. [Medline]

4) Gescheider GA, Bolanowski SJ, Hardick KR (2001) The frequency selectivity of information-processing channels in the tactile sensory system. Somatosens Mot Res 18, 191-201. [Medline] [CrossRef]

5) Bolanowski SJ, Gescheider GA, Verrillo RT, Checkosky CM (1988) Four channels mediate the mechanical aspects of touch. J Acoust Soc Am 84, 1680-94. [Medline] [CrossRef]

6) Morioka M, Griffin MJ (2008) Absolute thresholds for the perception of fore-and-aft, lateral and vertical vibration at the hand, the seat, and the foot. J Sound Vibrat 314, 357-70. [CrossRef]

7) Morioka M, Griffin MJ (2005) Thresholds for the perception of hand-transmitted vibration: Dependence on contact area and contact location. Somatosens Mot Res 22, 281-97. [Medline] [CrossRef]

8) Bolanowski SJ Jr, Verrillo RT (1982) Temperature and criterion effects in a somatosensory subsystem: 
A neurophysiological and psychophysical study. J Neurophysiol 48, 836-55. [Medline]

9) Green BG (1977) The effect of skin temperature on vibrotactile sensitivity. Percept Psychophys 21, 243-8. [CrossRef]

10) Harada N, Griffin MJ (1991) Factors influencing vibration sense thresholds used to assess occupational exposures to hand transmitted vibration. Br J Ind Med 48, 185-92. [Medline]

11) Lindsell CJ, Griffin MJ (2002) Normative data for vascular and neurological tests of the hand-arm vibration syndrome. Int Arch Occup Environ Health 75, 43-54. [Medline]

12) Griffin MJ, Bovenzi M (2002) The diagnosis of disorders caused by hand-transmitted vibration: Southampton Workshop 2000. Int Arch Occup Environ Health 75, 1-5. [Medline]

13) Griffin MJ (2008) Measurement, evaluation, and assessment of peripheral neurological disorders caused by hand-transmitted vibration. Int Arch Occup Environ Health 81, 559-73. [Medline] [CrossRef]

14) Bovenzi M, Ronchese F, Mauro M (2011) A longitudinal study of peripheral sensory function in vibration-exposed workers. Int Arch Occup Environ Health 84, 325-34. [Medline] [CrossRef]

15) Seah SA, Griffin MJ (2011) Thermotactile thresholds before, during and after exposure to hand-transmitted vibration. Proceedings of the $12^{\text {th }}$ International Conference on Hand-Arm Vibration, Ottawa, Canada, $13^{\text {th }}$ to $17^{\text {th }}$ June 2011.

16) Miwa $T$ (1967) Evaluation methods for vibration effects. Part 3: Measurements of threshold and equal sensation contours on hand for vertical and horizontal sinusoidal vibrations. Ind Health 5, 213-20. [CrossRef]

17) Miwa $T$ (1968) Evaluation methods for vibration effect. Part 6. Measurements of unpleasant and tolerance limit levels for sinusoidal vibrations. Ind Health 2, 18-27. [CrossRef]

18) Griffin MJ (1990) Handbook of human vibration. Academic Press, London.

19) Griffin MJ (1997) Measurement, evaluation, and assessment of occupational exposures to hand-transmitted vibration. Occup Environ Med 54, 73-89. [Medline] [CrossRef]

20) Griffin MJ (2004) Minimum health and safety requirements for workers exposed to hand-transmitted vibration and whole-body vibration in the European Union; a review. Occup Environ Med 61, 387-97. [Medline] [CrossRef]

21) Anon (1970) Sub-committee on hazards from local vibration. Jpn J Ind Health 12, 198-203.

22) ISO Draft Standard DIS 5349 (1979) Principles for the measurement and the evaluation of human exposure to vibration transmitted to the hand. International Organization for Standardization, Geneva.

23) ISO 5349-1 (2001) Mechanical vibration - measurement and evaluation of human exposure to hand-transmitted vibration - Part 1: General requirements. International
Organization for Standardization, Geneva.

24) ISO 8041 (2005) Human response to vibration Measuring instrumentation. International Organization for Standardization, Geneva.

25) Reynolds RR, Standlee KG, Angevine EN (1977) Handarm vibration, Part III: Subjective response characteristics of individuals to hand-induced vibration. J Sound Vibrat 51, 267-82. [CrossRef]

26) Morioka M, Griffin MJ (2006) Magnitude dependence of equivalent comfort contours for fore-and-aft, lateral and vertical hand-transmitted vibration. J Sound Vibrat 295, 633-48. [CrossRef]

27) Morioka M, Griffin MJ (2009) Equivalent comfort contours for vertical vibration of steering wheels: effect of vibration magnitude, grip force, and hand position. Appl Ergon 40, 817-25. [Medline] [CrossRef]

28) Hyvärinen J, Pyykkö I, Sundberg S (1973) Vibration frequencies and amplitudes in the etiology of traumatic vasospastic disease. Lancet 301, 791-4. [Medline] [CrossRef]

29) Welsh CL (1980) The effect of vibration on digital blood flow. Br J Surg 67, 708-10. [Medline] [CrossRef]

30) Nohara S, Okamoto K, Okada A (1986) Peripheral circulatory and nervous response to various frequencies of local vibration exposure. Scand J Work Environ Health 12, $382-4$.

31) Furuta M, Sakakibara H, Miyao M, Kondo T, Yamada $S$ (1991) Effect of vibration frequency on finger blood flow. Int Arch Occup Environ Health 63, 221-4. [Medline] [CrossRef]

32) Kent PJ, Williams G, Kester RC (1991) Altered sensitivity of digital blood flow to acute vibration in patients with vasospastic disease. J Biomed Eng 13, 269-71. [Medline] [CrossRef]

33) Bovenzi M, Griffin MJ (1997) Haemodynamic changes in ipsilateral and contralateral fingers caused by acute exposures to hand transmitted vibration. Occup Environ Med 54, 566-76. [Medline] [CrossRef]

34) Bovenzi M, Lindsell CJ, Griffin MJ (2000) Acute vascular responses to the frequency of vibration transmitted to the hand. Occup Environ Med 57, 422-30. [Medline] [CrossRef]

35) Bovenzi M, Welsh AJL, Della Vedova A, Griffin MJ (2006) Acute effects of force and vibration on finger blood flow. Occup Environ Med 63, 84-91. [Medline] [CrossRef]

36) Bovenzi M, Lindsell CJ, Griffin MJ (1999) Magnitude of acute exposure to vibration and finger circulation. Scand $\mathrm{J}$ Work Environ Health 25, 278-84. [Medline] [CrossRef]

37) Bovenzi M, Lindsell CJ, Griffin MJ (2001) Response of finger circulation to energy equivalent combinations of magnitude and duration of vibration. Occup Environ Med 58, 185-93. [Medline] [CrossRef]

38) Bovenzi M, Lindsell CJ, Griffin MJ (1998) Duration of acute exposure to vibration and finger circulation. Scand J Work Environ Health 24, 130-7. [Medline] [CrossRef] 
39) Bovenzi M, Welsh AJL, Griffin MJ (2004) Acute effects of continuous and intermittent vibration on finger circulation. Int Arch Occup Environ Health 77, 255-63. [Medline] [CrossRef]

40) Griffin MJ, Welsh AJL, Bovenzi M (2006) Acute response of finger circulation of force and vibration applied to the palm of the hand. Scand J Work Environ Health 32, 383-91. [Medline] [CrossRef]

41) Thompson AJL, Griffin MJ (2009) Effect of the magnitude and frequency of hand-transmitted vibration on finger blood flow during and after exposure to vibration. Int Arch Occup Environ Health 82, 1151-62. [Medline] [CrossRef]

42) Ye Y, Griffin MJ (2011) Reductions in finger blood flow in men and women induced by $125-\mathrm{Hz}$ vibration: association with vibration perception thresholds. J Appl Physiol 111, 1606-13. [Medline] [CrossRef]

43) Ye Y, Griffin MJ (2011) Effects of temperature on reductions in finger blood flow induced by vibration.
Int Arch Occup Environ Health 84, 315-23. [Medline] [CrossRef]

44) Ye Y, Griffin MJ (2012) Reductions in finger blood flow induced by $125-\mathrm{Hz}$ vibration: effect of area of contact with vibration.

45) Concettoni E, Griffin MJ (2009) The apparent mass and mechanical impedance of the hand and the transmission of vibration to the fingers, hand, and arm. J Sound Vibrat 325, 664-78. [CrossRef]

46) Griffin MJ (1994) Foundations of hand-transmitted vibration standards. Nagoya J Med Sci 57, 147-64. [Medline]

47) Griffin MJ (1998) Evaluating the effectiveness of gloves in reducing the hazards of hand-transmitted vibration. Occup Environ Med 55, 340-8. [Medline] [CrossRef]

48) Griffin MJ (2007) Discomfort from feeling vehicle vibration. Veh Syst Dyn 45, 679-98. [CrossRef] 